\title{
Michael J. Sailor: Porous Silicon in Practice. Preparation, Characterization and Applications
}

\author{
Peter Myers
}

Published online: 26 March 2013

(c) Springer-Verlag Berlin Heidelberg 2013

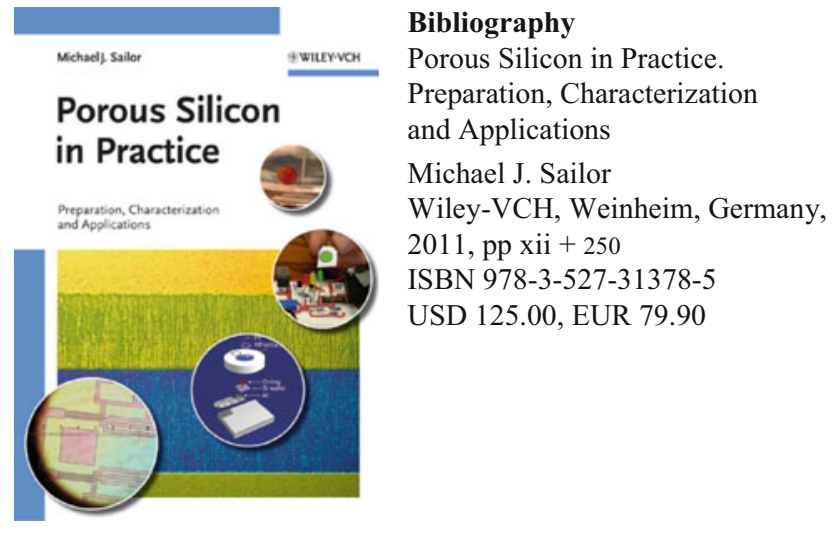

This book presents a real conflict for me in that the author states it is written for the beginner, even to the extent of someone who has no previous training in the field, but then goes on to describe the use of hydrofluoric acid. The use of $\mathrm{HF}$ is not for a beginner in any field. It would not have been so bad if the safety precautions given in the book for the handling of HF came close to what I consider to be the minimal level, but they do not. I would even go as far as suggesting to the publishers that a second edition this book should be published at the earliest opportunity with a safety chapter on the use of HF provided at the front of the book. As it is the Internet has a number of sites that give standard operating procedures for the handling of $\mathrm{HF}$ and these must be consulted in conjunction with this book.

The book also provides design diagrams for gas dosing cells. If these are to be used they should first be taken to a qualified engineer to obtain the correct specifications for the materials and obtain information on how they should be tested before use.

For the rest of the book it is what it says it is, a step-by-step instruction set on how to prepare and test major types of porous silicon. The author says the experiments are taken from assignments he has set and has since developed and enhanced. The join is not very good and in some cases the jump between experimental and theory is too big. For me the most interesting chapter was the last, Chapter 6 , on the chemistry of porous silicon. But again a lack of safety awareness is shown when the author only recommends the use of a microwave reactor designed for general chemical reactions.

So in conclusion I could only recommend this book to an experienced lecturer who wants to run lab classes on porous silicon. And to someone who will stress the safety requirements required to work with HF. It is not for a beginner. 